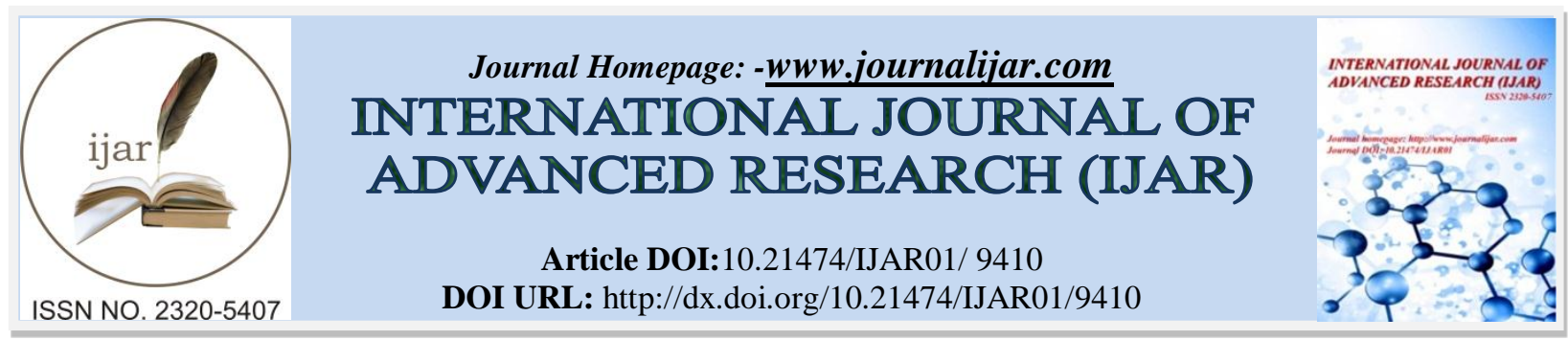

RESEARCH ARTICLE

\title{
A GLANCE AT JOB SATISFACTION THROUGH OCTAPACE CULTURE: AN EMPIRICAL STUDY OF SOFTWARE EMPLOYEES.
}

Dr. Tamizharasi ${ }^{1}$ and K. MeenaDevi ${ }^{2}$.

1. Dean R\&D, Department of MBA, RNSIT, Bangalore.

2. Asst Professor, Department of MBA, RNSIT, Bangalore.

\section{Manuscript Info}

Manuscript History

Received: 20 May 2019

Final Accepted: 22 June 2019

Published: July 2019

Key words:-

Culture, Involvement, Satisfaction,

Collaboration, Teamwork.

\begin{abstract}
Culture is defined as the mind-set, morals and viewpoint of a particular social, cultural or age group. Understanding organizational culture helps to raise the organizational efficiency and growth. The tool used in this study is OCTAPACE outline which is put in front by Udai $\mathrm{K}$. Pareek. The OCTAPACE profile is a 40 -item tool that gives the profile of organization's culture in eight values. The research conducted through the study is descriptive research. A total of 484 software employees were selected for study. The study revealed that few of the OCTAPACE culture dimensions show value lesser than the norms specified and there are variation on dimensions in organization. Teamwork and Trust among employees should be created among employees which is necessary for all organization for its efficiency. The present study aims to discover the relationship between OCTAPACE Culture and job satisfaction among software professionals in Bangalore.
\end{abstract}

Copy Right, IJAR, 2019,. All rights reserved.

\section{Introduction:-}

Organization culture has an rising importance because of the impact on job satisfaction. Understanding organizational culture helps to increase the organizational efficiency and growth. It helps to build up strong business identity. It is the system of shared meaning. It is the set of assumptions, beliefs, values and norms that is shared by an organization's members.

Culture comprise the representative side of an organization, and it shapes the human thought and behaviour in the system. The topic of organizational culture is common in use since the year 1980s. Organizational research initially focused highly on the survey of business climate, but in the yaer 1980s, the organizational environment notion was to a certain extent replaced by the idea of organizational culture.

\section{Organizational Culture}

Organizational culture is defined in terms of shared meanings - patterns of beliefs, rituals, symbols, and myths that evolve over time, serving to decrease human inconsistency and control and shape employee behaviour in organizations - Peters \& Waterman (1982) OCTAPACE CULTURE

Organizational culture includes ethics, values, beliefs, attitudes, norms, ethos, climate, environment, and culture. According to Udai Pareek, the Culture-related concepts also can be seen as multilevel concepts. At the core (first 
level) are the values, which give a distinct identity to a group. This is the basic ethos of the group. Pareek defines ethos as "Underlying spirit of character or group and is the root of culture". The second level concept is "climate", which can be defined as the perceived attributes of an organization and its members, groups and issues. The third level concept relates to "atmosphere", which is the distinct factor that affects the development of someone or something.

\section{Eight Dimensions Of Octapace}

The eight dimensions of OCTAPACE culture are Openness, Confrontation, Trust, Authenticity, Pro - action, Autonomy, Collaboration, and Experimentation which are essential for a strong and successful organization.

IMPORTANCE

Openness is degree of freedom in organisation. An open environment allow efficient work in organisation. Openness is defined as spontaneous expression of feelings and thoughts, sharing of these without defensiveness. Openness is both give and take. It leads to more unbiased performance feedback, greater clarity of objectives and free communication among people.

Confrontation is element which stresses on conflict, dispute settlement in organisation. It can be defined as facing problems rather than avoiding them. This involve taking up challenges along with deeper analysis of interpersonal problems.

Trust is extent of confidence and belief present in organisation. Trust is something that comes of its own without being ordered but as a result of experience. This component in organisation helps employees to freely talk and share their opinion with each other. It is determined by maintaining confidentiality of sharing information and not misusing it. It also promotes mutual help and understanding which ensures sense of guarantee that others will help when needed.

Autonomy is freedom that is given to employees of organisation in order to work in their own way as everyone has a pattern of doing or getting work done. This will enhance creativity and innovation in organisation. It means respecting and encouraging individual and role autonomy. It also develops mutual respect and promotes willingness of employees to take responsibility, initiative and succession planning.

Proactivity is the other name of forward thinking. It means taking initiative, preplanning and taking preventive action and calculating payoffs for alternative course before taking action. It may involve new unusual behaviour or starting a new process altogether. Authenticity focuses on ethical and lawful processes used in organisation. It is defined as resemblance between what one says and does. It is close to openness.

Authenticity leads to reduced distortion of in communication. This can be seen as correspondence among members of organisation.

Collaboration is scale of team work in organisation. Employees work in collaboration which enhance their performance. It means helping others and asking for help when required. It is working together to solve problems and in team spirit. It leads to timely help, team work, sharing of experiences, improved communication and improved resource sharing.

Experimentation is application of learned skill and knowledge. Employees in an organisation should be given opportunity to show and apply what they have learnt. This will lead to invent new ideas and innovation benefiting organisation overall. It involves using new and different ways to work rather than traditional methods, using feedback for improvement, looking at things from different angle and stimulating creativity.

\section{Review Of Literature}

Nazir A Nazir (2005) surveyed Person-lifestyle Fit and Employee Commitment in Banks. Main findings of study showed slight to strong character-culture match score became determined in a single personal and two foreign banks and weak to slight individual-culture in shape rating become discovered in relaxation of banks studied. Research on OCTAPACE culture for advertising employees in selected IT agencies of India by confirmed that sample employer differed notably in their OCTAPACE culture and having various level of OCTAPACE way of life. 
Mufeed, Hamdani \& Mufeed (2015) labored on locating organisational way of life and its impact on increase in health care area in Jammu \& Kashmir. The research discovered that the organisational way of life had an effect on the behaviour, performance, expertise management of employees. It suggested that lifestyle impacts remarks method, organisational effectiveness, found out helplessness, overall efficient protection and agency dynamism of employees. Researcher said that establishments need to focus more on appropriate lifestyle to make certain pride of personnel so that productivity and effectiveness can be better.

Subhramanian \& Renganthan (2013) has evaluated personnel' angle towards agency subculture in Automobile Industries with unique connection with Chennai city. The purpose of this take a look at turned into to examine worker's perspective in the direction of present organisational culture and practices in car industry, to determine openness and consider prevailing in business enterprise, to find out employees' opinion toward authenticity and teamwork prevailing in agency and to decide their outlook in the direction of proactive and progressive measures taken by means of management. In this observe researcher has made an attempt to study employee's intuitivism in the direction of current Organisation tradition and practices at automobile agencies for which the researcher set objectives based on dimensions of Organisation way of life and made use of OCTAPACE device rely and customised it consistent with requirement of business enterprise based totally upon which questionnaire became constructed.

Jayanthi \& Bhuvaneshwaari (2014) had carried out a comparable have a look at on OCTAPACE in Ponni Sugars Erode Pvt Limited the usage of OCTAPACE framework. This examine goals at figuring out outlook of employees towards proactive and revolutionary measures taken by management as well as figuring out and measuring values and belief of personnel touching on OCTAPACE culture of their organizations. As some distance as dimensions of OCTAPACE are concerned, collaboration ranked first amongst the ethos of corporation way of life, following authenticity, autonomy, consider, proactivity, openness and disagreement. In comparison to dimensions of OCTAPACE war of words ranked lowest.

Jallavi \& Petonjee (2015) studied organisational lifestyle in Power zone firms which became an try to compare cultural ethos using OCTAPACE profile which suggests how an awful lot every ethos is valued and believed by means of managerial and non - managerial personnel of strength zone organisations. The calculated way of OCTAPACE ethos of tradition had been compared with low and excessive norms of OCTAPACE. It is seen that Authenticity become lowest valued in comparison to other ethos whilst Autonomy and Experimentation are in the direction of better quit of cautioned norms even as suggest score of Openness, Confrontation and Trust were located to be closer to decrease give up of norms. It is depicted from results that personnel perceive their boss and their colleagues to be proper in their behaviour.

Sulakshna, Sanjay and Luxmi (2013) have emphasised impact of organisational culture on turnover intentions of employees in BPO Sector. Present study has been carried out round Chandigarh to establish a dating amongst Organisational Culture, Commitment, and Turnover Intentions of personnel. Conclusion is that turnover aim of employees in BPO area is motivated by means of organisational subculture and commitment. It way more BPO personnel understand organisational tradition positively, the less probable they intend to give up.

Salman Habib, Aslam, Hussain, Yasmeen \& Ibrahim (2014) performed a take a look at at the impact of organisational lifestyle on activity pride, Employees dedication and Turnover intentions. Results indicated that nature of business enterprise notably consequences on Job Satisfaction and turnover intentions. So, findings of research proved that organisational culture is essential detail which relatively influences employee commitment, activity delight and retention.

\section{Objectives For The Study}

1. To pick out the variables to degree the way of life at organizational and go-practical level.

2. To analyze the variables influencing OCTAPACE tradition at employer level.

3. To analyze the connection of lifestyle on process pride.

\section{Method Of Investigation}

The research performed is thru descriptive research. A descriptive examine is under taken in an effort to ascertain and to explain the traits of variables of hobby in a scenario. The purpose of choosing descriptive layout is to acquire 
new insights into the lifestyle, to formulate a whole and comprehensive image of organizational culture affecting the well being of software program personnel.

The have a look at specializes in organizational culture skilled via software personnel (IT Professionals). Convenient Sampling Technique has been followed in this look at. A total of 484 software program employees were selected for the observe. The look at became undertaken in Bangalore that's a known as because the IT hub where many remarkable IT businesses are placed and from which records has been amassed. The facts were analyzed the use of "SPSS".

\section{Instrument Used}

The device used in this look at is OCTAPACE Profile that is proposed through Udai k. Pareek. The OCTAPACE profile is a 40-object instrument that offers the profile of company's ethos in eight values. These values are openness, confrontation, trust, authenticity, proaction, autonomy, collaboration and experimentation.

The device used to degree job satisfaction is spector's scale that is a 9 side scale that offers with salary, promotion, work conditions, supervision, co-workers, nature of the job, communication, contingent rewards, fringe benefits, job security, sense of belongingness.

\section{Questionnaire Design}

The questionnaire incorporates 40 questions framed on 5 factor score scale.

The device consists of two components. In element I, values are stated in objects 1 to 24 (three statements of every of the eight values), and the respondent is required to check (on a 4-point scale) how lots every Item is valued in his agency. Part 2 incorporates 16 statements on beliefs, two every for eight values, and the respondent assessments (on a 4-point scale) how widely each of them is shared inside the employer.

\section{Hypothesis}

H0: There is a significant relationship between the OCTAPACE culture and job satisfaction among software professionals in Bangalore

H02: OCTAPACE Culture doesn't impact the job satisfaction of software professionals in Bangalore.

Reliability of the scales:

Alpha (Cronbach's) reliability of the 2 scales used is

OCTAPACE Culture $=$ zero. 88 , Job Satisfaction $=0.95$

This indicates a completely excessive inner reliability, based totally on common inter-item correlation.

\section{Data analysis and interpretations:}

As consistent with the table of OCTAPACE Values, the mean rating for Item No.1 (3.Sixty seven), item No.3 (3.Fifty six) and Item No. 8 (3.49) have been determined to be better than other item which shows that employees in the agency, consider each different and they're not afraid to specific or talk the emotions with their subordinates, they confront their problem rather than accusing every different at the back of the back.

Table 1:-(item wise mean score, OCTAPACE Culture)

\begin{tabular}{|c|c|c|c|}
\hline Sl No & Statements & Mean & SD \\
\hline 1 & People trust each other in this organization. & 3.6761 & 0.92234 \\
\hline 2 & $\begin{array}{l}\text { Employees do not feel afraid about their expression of/or discussion of } \\
\text { their feelings with their superiors. }\end{array}$ & 3.3239 & 0.96769 \\
\hline 3 & $\begin{array}{l}\text { Employees are not afraid to express or discuss their feelings with their } \\
\text { subordinates. }\end{array}$ & 3.5634 & 0.90605 \\
\hline 4 & $\begin{array}{l}\text { Employees are encouraged to take initiative and do things on their own without } \\
\text { having to waitvfor instructions from supervisors. }\end{array}$ & 3.1268 & 1.04101 \\
\hline 5 & $\begin{array}{l}\text { Delegation of authority to encourage juniors to develop handling higher } \\
\text { responsibilities is quite common in this organization. }\end{array}$ & 3.0845 & 1.07897 \\
\hline 6 & $\begin{array}{l}\text { When seniors delegate authority to juniors, the juniors use it as an } \\
\text { opportunity for development. }\end{array}$ & 3.3803 & 0.88425 \\
\hline
\end{tabular}




\begin{tabular}{|l|l|l|l|}
\hline 7 & $\begin{array}{l}\text { We have the system of facing challenges inherent in the work } \\
\text { situation. }\end{array}$ & 3.6813 & 0.88635 \\
\hline 8 & $\begin{array}{l}\text { When problems arise people discuss these problems openly and try to solve them } \\
\text { rather than keep accusing each other behind the back. }\end{array}$ & 3.4930 & 0.89240 \\
\hline 9 & $\begin{array}{l}\text { Career opportunities are pointed out to juniors by senior officers in } \\
\text { the organization. }\end{array}$ & 2.7746 & 1.05826 \\
& $\begin{array}{l}\text { The organization's future plans are made known to the managerial staff to help } \\
\text { them develop their juniors and prepare them for future. }\end{array}$ & 2.9437 & 1.08084 \\
\hline 10 & \multicolumn{1}{|l|}{ Overall $\boldsymbol{O C T A P A C E} \boldsymbol{C U L T U R \boldsymbol { E }}$} & 3.2700 & 0.57581 \\
\hline
\end{tabular}

\section{Job Satisfaction:}

The item wise mean scores of the total sample of the software professionals are presented in the Table 2 . Since the questionnaire used is 5 point scale, ranging from 5 strongly agree to 1 strongly disagree. Here the overall score was 3.27 which indicates that job satisfaction level of employees is just above average. Examining the scores of the individual items of the JS Scale, the researcher found that the mean scores of the items no.1 (3.76), 5(3.70), $4(3.69)$ and $18 \mathrm{~b}$ (3.56) are higher than other items in the scale which indicates that the employees are highly satisfied with the availability as well as adequacy of opportunities to do different things from time to time which make use of their abilities along with this they are also contended with the stability in employment. On the whole the results showed that people are happy with the work and the organization in general.

\section{Hypothesis}

H0: There is a significant relationship between the OCTAPACE culture and job satisfaction among software professionals in Bangalore

\begin{tabular}{|l|l|r|r|}
\hline \multicolumn{2}{|c|}{ Correlations } & Organization Culture \\
\hline \multirow{4}{*}{ Organization Culture } & Pearson Correlation & 1 & $.763^{* *}$ \\
\cline { 2 - 4 } & Sig. (2-tailed) & 484 & .000 \\
\cline { 2 - 4 } & $\mathrm{N}$ & $.763^{* *}$ & .000 \\
\hline \multirow{5}{*}{ Job Satisfaction } & Pearson Correlation & 484 \\
\cline { 2 - 4 } & Sig. (2-tailed) & 484 & 1 \\
\cline { 2 - 4 } & $\mathrm{N}$ & & 484 \\
\hline \multirow{2}{*}{$* *$ Correlation is significant at the 0.01 level (2-tailed). } & \\
\hline
\end{tabular}

\section{Interpretation}

The above desk shows the connection between Organization Culture and Job Satisfaction. The table means that there is high quality correlation between both the variables. Since P fee is 0.000 that's much less than 0.05 as a result reject $\mathrm{H0}$ and accept opportunity speculation. The correlation coefficient was zero.763 (JS*OCTAPACE Culture), this indicates that OCTAPACE Culture is a contributing/influencing component to boom the level of job satisfaction some of the software program specialists. Thus, our set hypothesis stand everyday.

\section{Findings and Conclusion:-}

The fundamental objective of this look at become to assess the quantity of OCTAPACE Culture triumphing in IT agencies. The findings of the present have a look at imply that the software employees understand that OCTAPACE culture in IT corporations is at a notably properly level. The have a look at means that openness of group of workers with their subordinates and superiors and mindset of collaboration have contributed to keep the OCTAPACE way of life still at upper degree. The consequences of gift study recommend that there is nonetheless a enormous scope for improvement of diverse factors of OCTAPACE Culture. In creating favorable OCTAPACE subculture groups must placed honest efforts to entrench the values of war of words, autonomy, authenticity and pro-pastime in IT corporations at Bangalore. Further it changed into found that OCTAPACE Culture contributed in improving task pleasure among IT experts.

Based on the findings of gift have a look at it's miles enormously endorsed for the employer to provide a congenial OCTAPACE Culture on the way to make certain the lifestyles of excessive degree of delight among their employees on the way to return in excessive organizational efficiency and effectiveness. 


\section{Ending Remarks}

The organizational lifestyle at adrenalin structures Ltd is proper normal with understand to the vital dimensions required for a software application business enterprise which includes pre making plans, trust, loose conversation amongst personnel. Some of the scale of OCTAPACE culture viz, Authenticity, Autonomy and experimentation shows decrease limit than general norms, which calls for similarly research. Collaboration and accept as real with among personnel should be cultivated amongst personnel this is important for each commercial enterprise employer for its effectiveness. Thus, the manage must work for broaden the organizational manner of life that requires the way of existence of openness, collaboration, be given as real with, pro-hobby, autonomy, authenticity, conflict of words and experimentation, which is interconnected and critical for each enterprise for its improvement.

\section{Limitations of the Study}

1. The present study was confined to study the only 8 elements of culture.

2. The present study was confined to study the OCTAPACE Culture prevailing in the selected IT companies in Bangalore.

3. The findings may not be same all over India, since the software employee's perception is likely to vary depending upon the prevalent environment.

4. The sample size was restricted to 484 software professionals belonging to only 23 different IT organization of Bangalore due to the scarcity of time and adequate financial resources.

\section{References:-}

1. Gordon, George G. "Industry Determinants of Organizational Culture." Academy of Management Review. April 1991.

2. Pareek U (2002), "Training gadgets in HRD and OD”, Tata McGraw -Hill, New Delhi

3. three. Stephen P. Robbins, "Organization Theory: Structure, Design and Applications"

4. four. Dr.K.Ashwathappa, "Organization Behavior", Himalaya Publications five.

5. Five. John W. Newstrom, "Human Behavior at work"

6. Erakovich R, "A take a look at on courting of moral work climate and organizational subculture in public agencies", Paper presented at American Society for public administration.

7. Feza Tabassum Azmi and Richa Sharma, Profiling OCTAPACE tradition: An empirical take a look at of banking and IT sectors in India”, The Icfaian Journal of Management Research, Vol VI, www.Iupindia.Org. December 2007

8. 8. Srivastava s okay and srinivasa $\mathrm{p}$ (2004)," performance enhancement through continuous improvement ",paper supplied at 2nd global convention on POM.

9. 9. Srivastav a k, "Teaming paintings via ISO 9000-A Reality", Proceedings annual nice Congress.

10. 10. Prof. Bhavna Chandak and Dr. Babita Agarwal, "The effect of OCTAPACE subculture on TPM". 